\title{
Vantagem competitiva sob a luz da teoria RBV: uma análise no pólo de confeç̧ões de Pernambuco
}

A região do Pólo de Confecções do Agreste de Pernambuco conta com milhares de unidades produtivas formais e informais. Embora algumas destas unidades apresentem um desempenho superior no mercado, este desempenho ainda não é compreendido, ou seja, a forma como estas obtém vantagem competitiva não é explicada por teorias do contexto organizacional. A importância de se estudar o fenômeno da vantagem competitiva nas empresas da região se dá pela alta competitividade que o setor possui, nos números de produção e vendas e no conjunto de recursos possuídos pelas empresas. A fim de identificar a vantagem competitiva e suas fontes, esta pesquisa tem como objetivo geral analisar as implicações competitivas nas empresas estudadas no Pólo de Confecção do Agreste de Pernambuco de acordo com os pressupostos da RBV. A coleta dos dados foi realizada por meio de entrevista semiestruturada, bem como aplicação de questionário. $\mathrm{O}$ trabalho conduziu aos resultados de que as empresas possuem um conjunto de recursos valiosos, raros, difíceis de imitar e que a organização explora. Alguns dos recursos considerados estratégicos e identificados pela pesquisa foram: o software de frente de caixa (Empresa A), o valor da marca (Empresa B), o marketing digital (Empresa D) e o software de criação (Empresa E). Enquanto que na Empresa B todos os recursos foram considerados estratégicos. Isso implicou em uma vantagem competitiva temporária, paridade competitiva e desvantagem competitiva para as empresas pesquisadas, sendo que nenhuma delas alcançou vantagem competitiva sustentável, o ideal.

Palavras-chave: Pólo de Confecções; Vantagem Competitiva; Resourced-Based View.

\section{Competitive advantage through the light of the RBV theory: an analysis of the clothing cluster in Pernambuco}

The clothing cluster in Pernambuco has thousands of formal and informal productive units. Although some of these units perform better on the market, this performance is still not understood, that is, the way they gain competitive advantage is not explained by theories of the organizational context. The importance of studying the phenomenon of competitive advantage in companies in the region is due to the high competitiveness that the sector has, in the production and sales numbers and in the set of resources owned by the companies. In order to identify the competitive advantage and its sources, this research has as general objective to analyze the competitive implications in the companies studied in the clothing cluster in Pernambuco according to the assumptions of the RBV. In order to achieve this goal, the data were collected through a semistructured interview, as well as questionnaire application. The work has led to the finding that companies have a number of valuable, rare, hard-to-imitate resources that the organization explores. Some of the resources considered strategic and identified by the research were: cashier software (Company A), brand value (Company B), digital marketing (Company D) and creation software (Company E). While in Company B all resources were considered strategic. This implied a temporary competitive advantage, competitive parity and competitive disadvantage for the companies surveyed, none of which achieved a sustainable competitive advantage, the ideal.

Keywords: Clothing Cluster; Advantage Competitive; Resource-Based View.

\section{Topic: Planejamento, Estratégia e Competitividade}

Reviewed anonymously in the process of blind peer.

Valmir Fernandes de Araújo

Universidade Federal de Pernambuco, Brasil

http://lattes.cnpq.br/5295348922573488

fernandes.ufpe2012.2@gmail.com

\section{José Cícero Castro}

Universidade Federal de Pernambuco, Brasil

http://lattes.cnpq.br/9142857434310773

jccastroprofessor@gmail.com

Marconi Freitas da Costa

Universidade Federal de Pernambuco, Brasil

http://lattes.cnpq.br/7359522003689133

marconi_costa@hotmail.com
Received: 09/05/2017

Approved: 08/07/2017
Referencing this:

ARAÚJO, V. F.; CASTRO, J. C.; COSTA, M. F.. Vantagem competitiva sob a luz da teoria RBV: uma análise no pólo de confecções de Pernambuco. Revista Brasileira de Administração Científica, v.8, n.2, p.97-115, 2017. DOI: http://doi.org/10.6008/SPC2179684X.2017.002.0007 


\section{INTRODUÇÃO}

A Indústria de Transformação é formada por diversos setores, entre estes está o da indústria têxtil e de confecção de artigos do vestuário. De acordo com o IEMI (2015), entre 2010 e 2014 o segmento de confeç̧ão de vestuário cresceu $7,6 \%$, enquanto os investimentos em modernização e/ou ampliação da capacidade produtiva aumentaram $8,1 \%$ e os investimentos em máquinas e equipamentos apresentaram crescimento de $21,9 \%$.

Em relação ao estado de Pernambuco, em 2013 o setor de confecção representou 1,7\% do PIB industrial, ou seja, contribui com $\mathrm{R} \$ 350,2 \mathrm{mi}(\mathrm{CNI}, 2016)$. Duas regiões são as principais responsáveis pela produção de vestuário no estado, a Região Metropolitana de Recife (RMR) e a Região Agreste do estado, mais precisamente o Polo de Confecções do Agreste de Pernambuco (SEBRAE, 2012).

O Polo de Confecções do Agreste de Pernambuco é considerado o segundo maior Polo de confecções do Brasil, atrás apenas da região do Braz, em São Paulo (LACERDA, 2013). A região possui aproximadamente 19 mil unidades produtivas (formais e informais), sendo Caruaru $(24,1 \%)$, Santa Cruz do Capibaribe $(38,1 \%)$ e Toritama (15\%) as cidades que mais detém unidades produtivas em seus territórios. O faturamento é de aproximadamente $\mathrm{R} \$ 1$ bi por ano, contando com a informalidade. A produção mensal, em $83 \%$ das unidades produtivas, não ultrapassa 5.000 mil peças. O número de pessoas empregadas é de cerca de 130 mil pessoas em 10 cidades. A estimativa é de que existam mais de 144 mil máquinas utilizadas na produção (SEBRAE, 2012).

O Polo trouxe uma abertura econômica e grandes mudanças, tanto na parte econômica quanto na parte administrativa das empresas que estão inseridas nesse mercado. Visto que essa região acumula um alto potencial de desenvolvimento e geração de riqueza, é cada vez maior o número de empresas que entram nesse mercado a fim de obter ganhos, tornando-o altamente competitivo e requerendo que as empresas desenvolvam formas de alcançar seus objetivos e, assim, obtenha vantagem competitiva (OLIVEIRA, 2011).

Diante do que já foi apresentado até aqui, os números mostram a importância do Polo, porém, eles por si só não explicam o sucesso dessa região e de algumas empresas que atuam neste mercado, ainda é algo desconhecido. Não há estudos que tentem explicar o fenômeno da vantagem competitiva nesta região sob nenhuma perspectiva teórico-empírica do campo da estratégia empresarial.

Este estudo apresenta um primeiro esboço na tentativa de compreender o fenômeno da vantagem competitiva sob um viés teórico-empírico da estratégia empresarial, a luz da teoria da visão baseada em recursos (RBV). Afinal, compreender a forma como as empresas alcançam e sustentam vantagem competitiva está no âmago das discussões no campo da estratégia (TEECE et al., 1997; KULL et al., 2016; BAYRAKTAR et al., 2017). Diante da alta competitividade do setor de confecção e das estratégias adotadas pelas empresas, onde algumas possuem um desempenho superior, surge a seguinte problemática: Qual o tipo de implicação competitiva que as empresas estudadas na região do Polo de Confecções do Agreste de Pernambuco alcançam de acordo com os pressupostos da Visão Baseada em Recursos?. 


\section{REVISÃO TEÓRICA}

\section{Visão Baseada em Recursos}

O viés teórico utilizado para tentar compreender o fenômeno da vantagem competitiva nas empresas está se disseminando no campo da estratégia e destaca o papel essencial que recursos e capacidades podem ter no alcance da vantagem competitiva para a empresa, tal teoria é a Visão Baseada em Recursos (Resource-Based View - RBV) (GOHR et al., 2011; RIBEIRO et al., 2012; ARIK et al., 2016). Autores do campo como Barney (1991) e Grant (1991) afirmam que os recursos são essenciais para que as empresas alcancem vantagem competitiva sustentável.

Vantagem competitiva é quando a empresa implementa uma estratégia de criação de valor que não pode ser simultaneamente implementada por qualquer outro competidor corrente ou potencial (BARNEY, 1991). Segundo Barney et al. (2007), a RBV é um modelo de desempenho com foco nos recursos e capacidades controladas por uma empresa como fontes de vantagem competitiva. Neste ínterim, as fontes de vantagem competitiva de uma empresa estão nos seus recursos únicos e as capacidades controladas por ela, desde que estes proporcionem uma maior geração de valor econômico do que os rivais. Sendo os recursos e capacidades fatores determinantes na busca de vantagem competitiva (EISENHARDT et al., 2000; CRUBELLATE et al., 2008).

Os recursos, de acordo com Lin et al. (2014), são entendidos como tudo aquilo que é usado no processo produtivo, podendo ser tanto tangíveis (máquinas, planta fabril, matéria-prima e etc.) quanto intangíveis (marcas, conhecimento dos colaboradores, reputação e etc.). As capacidades são subconjuntos destes recursos que são utilizados para implementar sua estratégia. Os recursos podem ser divididos em quatro categorias: recursos financeiros; recursos físicos; recursos humanos; e recursos organizacionais (BARNEY et al., 2007).

A RBV ajudou a enriquecer os estudos em estratégia, uma vez que, conforme Hoskisson et al. (1999) e Kull et al. (2016), mudou a direção dos estudos sobre vantagem competitiva, tirando-a do ambiente externo, como eram realizados os estudos baseados no modelo de economia da Organização Industrial, e trazendo a problemática para o ambiente interno das organizações, no caso, os recursos e capacidades internas.

Nos estudos enviesados na RBV, Barney et al. (2007) propõe o modelo VRIO a fim de analisar o potencial competitivo de recursos e capacidades da empresa sob quatro questões: a questão do Valor, da Raridade, da Imitabilidade e da Organização. O modelo conduz a uma análise baseada em recursos a fim de responder as perguntas relacionadas a cada uma das quatro questões (LAMB et al., 2009). De acordo com cada resposta dada às perguntas levantadas é possível avaliar as implicações competitivas da empresa, bem como a relação entre forças e fraquezas organizacionais. De posse de recursos valiosos, raros, difíceis de imitar e explorados pela organização, é possível elaborar estratégias que neutralizem uma ameaça do ambiente ao mesmo tempo em que explora uma oportunidade (BARNEY et al., 2007). 


\section{METODOLOGIA}

Para realizar este estudo foi empregada uma pesquisa qualitativa, a qual permite explorar, explanar e descrever um fenômeno (MARSHALL et al., 2006). A população escolhida poderia ter sido qualquer uma situada em qualquer região do país, porém, o campo de estudo escolhido foi o Polo de Confecções do Agreste de Pernambuco e a amostra foram empresas situadas no campo. O critério de escolha do campo se deu pela facilidade de acesso e a representatividade da população-alvo, no caso, o Polo (VERGARA, 2010). A amostra contou com cinco empresas do setor de confecção no Polo de Confecções do Agreste de Pernambuco para poder identificar seus conjuntos de recursos e capacidades e identificar qual tipo de implicação competitiva estes recursos conferiam à empresa.

A fim de estudar mais detalhadamente o fenômeno da vantagem competitiva sob a luz da teoria RBV, o método de coleta de dados utilizado foi o estudo de casos. O estudo de caso apresenta como característica o foco em uma unidade que se analisa profundamente (GODOY, 1995). Como a pesquisa busca identificar o tipo de implicação competitiva das empresas pesquisadas de acordo com os pressupostos da RBV a fim de se desenvolver hipóteses acerca da vantagem competitiva, bem como explicar as variáveis que podem determinar este fenômeno (GIL, 2002), o método será o de estudo de casos múltiplos, ou seja, não será um caso único a ser estudado, mas sim nove casos inseridos no contexto da pesquisa. Yin (2005) mostra que proceder com uma pesquisa com estudos de casos múltiplos ajuda a ampliar os benefícios analíticos ao confrontarem-se realidades diferentes.

A coleta dos dados se deu por meio de questionário fechado e entrevista semiestruturada, uma vez que a pesquisa de campo inclui a aplicação destes. O questionário levantou dados para caracterizar a empresa, bem como buscou obter informações que fossem de encontro aos objetivos específicos. O número de entrevistados foi de cinco pessoas, uma para cada empresa, onde, entrevistou-se: na Empresa A, o gerente de uma das lojas; na Empresa B, a estilista; na Empresa C, o gerente financeiro sócio; na Empresa D, o diretor proprietário; e na Empresa E, o diretor-proprietário.

À formulação das perguntas dos questionários contou com pesquisas análogas a esta, como os trabalhos de Cunha Filho (2012) e Barbosa (2013), bem como formulação de questões próprias baseadas no referencial teórico abordado nesta pesquisa. $\mathrm{O}$ tempo de pesquisa de campo foi de onze dias para a aplicação do questionário e realização da entrevista. Os questionários foram aplicados no mesmo dia em que a entrevista foi realizada. As entrevistas aconteceram entre o final de Outubro e a segunda semana de Novembro. A transcrição das entrevistas, bem como a análise dos dados foi realizada logo após o término da pesquisa de campo.

\section{RESULTADOS E DISCUSSÃO}

A fim de alcançar o objetivo geral desta pesquisa, se levantou questões relacionadas aos recursos e capacidades na empresa de acordo coma perspectiva de autores como Wernerfelt (1984), Grant (1991), Barney (1991), Peteraf (1993) e Barney et al. (2007) em cada empresa individualmente. Para melhor entendimento, os entrevistados seguem a distinção de acordo com cada empresa, assim, por exemplo, o 
Entrevistado A corresponde a entrevista realizada na Empresa A. Os resultados individuais estão organizados nas seções a seguir de acordo com as respostas dadas por cada entrevistado nas empresas.

\section{Empresa A}

Os recursos tangíveis identificados na Empresa A foram: máquinas de última geração e com alta tecnologia; recursos financeiros próprios e ainda possui uma política de reter lucros para reinvestir no negócio; localização; lojas; fábrica; e matéria-prima. Os recursos intangíveis identificados foram: marca; softwares de monitoramento de tendências e concorrentes, produção e vendas; recursos organizacionais (estrutura formal de reporte, sistemas formais e informais de planejamento, controle e coordenação); conhecimento no ramo; conhecimento dos colaboradores. Os recursos citados são considerados forças para empresa, para isso o Entrevistado A afirma que '[...] a equipe da diretoria eles sempre buscam estar antenados na questão de produzir, sempre 'tá' à frente, buscando novidades, tanto na área pessoal, como também de funcionário, como também a questão de máquinas, sempre 'tá' a frente do nosso concorrente'.

Alguns dos recursos identificados, como a estrutura formal e informal de reporte, sistemas formais e informais de planejamento, controle e coordenação (recursos organizacionais) foram desenvolvidos com a ajuda de uma consultoria especializada que contribuiu para a setorização da empresa. Hoje a empresa está setorizada com um gerente a frente de cada setor, porém interagindo entre si. Em cada reunião os gerentes levam seus problemas, o que, posteriormente, será levado até a diretoria para ser discutido, tudo isso esquematizado no organograma da empresa.

Destes recursos mencionados, tanto tangíveis quanto intangíveis, além de forças, aquele considerado estratégico para a empresa é o software de monitoramento de tendências, concorrentes, produção e venda. A justificativa, conforme o Entrevistado A, é que '[...] eu consigo, por meio deste software, pesquisar o meu concorrente, o que ele tá produzindo, como 'tá' produzindo, o que ele 'tá' lançando e se 'tá' de acordo com a tendência, com a moda do momento. Então eu consigo mensurar isso, se eu estou na frente dele ou se eu estou atrás dele, entendeu? Esse software consegue me dar essa mensuração em relação a venda para o cliente final'.

Ele prossegue, dizendo: 'Eu consigo saber o perfil dele (cliente), assim, além do que ele gosta de usar, quanto tempo de rotatividade ele vem à minha loja, se ele vem duas vezes no mês, se ele vem três vezes no mês, se ele compra mensalmente, se ele compra a cada três meses e qual o valor de compra que ele compra por visita a loja'.

Sobre a marca da empresa como um recurso que pode proporcionar uma vantagem competitiva, sobre a consolidação, a forma como impacta no negócio da empresa e como é ela desenvolvida, o Entrevistado A afirma: 'A minha marca [...] ela tem crescido muito, ela é uma marca que tem trazido até status. [...] Nós estamos há 20 anos no mercado, nós inauguramos a nossa marca em 1996, estamos em 2016 'né', são 20 anos no mercado, já é uma marca que é conhecida no mercado. [...] E na questão do desenvolvimento a gente tem se preocupado com isso que a gente quer trazer para ao nosso cliente, não só que ele se vista bem, mas que [...] agregue valor à pessoa'. 
Todos os recursos são alocados e desenvolvidos levando em consideração as estratégias existentes e de acordo com estrutura da empresa. O Entrevistado A, neste ponto, afirma que 'não adianta querer lançar, fabricar um produto que eu não vou ter a capacidade de entregar perfeito, com a qualidade que eu pretendo que ele tenha, então assim, a gente tenta produzir realmente com qualidade, mas lógico, no que eu posso, porque seria até uma propaganda enganosa'.

Os recursos ora citados antes precisam ficar compatíveis e trabalhar de forma colaborativa, para isso, o Entrevistado A diz: 'Veja bem, de forma colaborativa a gente sempre busca fazer treinamento para o pessoal, certo, treinamento, aperfeiçoamento, entendeu? Aquela questão de sempre o pessoal buscar aperfeiçoar, inclusive a própria empresa ela sempre busca instigar o seu colaborador a estudar, a fazer um curso técnico, fazer uma faculdade para que o próprio colaborador ele cresça também, porque seu eu tenho um colaborador que tem conhecimento eu vou ganhar com isso, porque ele vai aplicar esse conhecimento na empresa'.

A Empresa A busca pesquisar os recursos dos concorrentes a fim de diagnosticar aqueles em comum. Na pesquisa sobre os recursos dos concorrentes são levantadas informações sobre o que estes estão produzindo e a tecnologia que estão utilizando, isso possibilita à empresa lançar um produto diferenciado no mercado.

A empresa investe em Pesquisa \& Desenvolvimento por meio de pesquisas e buscando especialistas da área de moda que tragam conhecimento para a empresa, auxiliando na antecipação de ameaças para que estas sejam neutralizadas. Um ponto da pesquisa foi levantado: a possibilidade de transferir para outra empresa os recursos e capacidades e se o desempenho seria o mesmo. Nesse ponto o Entrevistado A diz: 'Transferido eu acredito que sim, mas não seria o mesmo, por quê? Porque as pessoas seriam diferentes e hoje o que mais vale é o conhecimento'.

Em continuidade, o entrevistado prossegue: 'Eu posso usar como exemplo a questão do Windows de Bill Gates que ninguém até hoje conseguiu fabricar um produto nem similar ao Windows. Mesmo que ele passe para outra pessoa se ele não passar os profissionais, os técnicos que desenvolvem o Windows, o cara que detém o segredo mesmo, que a gente chama o 'pulo do gato', o cara não vai conseguir, ele faz similar, mas igual não'.

A importância do conjunto de recursos e capacidades da empresa é avaliada mensalmente de acordo com o Entrevistado A. Ele afirma que '[...] em reuniões gerenciais cada setor traz os pontos fortes e fracos, então estes são levantados e há a busca de uma melhor forma de se resolver possíveis problemas, evitando gargalos nos setores que possam vir a prejudicar o desempenho da empresa. Vale lembrar que a empresa utiliza recursos e capacidades como fonte para a elaboração das estratégias organizacionais. Uma coisa importante a ser fazer é proteger os recursos da empresa, sejam eles de quais tipos forem. Neste caso, a empresa busca sempre se informar através de pesquisas e informações'.

Conduzindo a pesquisa sobre vantagem competitiva sob a luz da teoria RBV, o modelo VRIO foi aplicado na Empresa A para se identificar o tipo de implicação competitiva que está possuí. O resultado encontrado na Empresa $A$ foi o de que esta possui uma paridade competitiva, o que também caracteriza uma 
força. Nesta empresa alguns recursos são raros, custosos de imitar e, apesar da empresa não operar com $100 \%$ de sua capacidade, são explorados pela organização.

A empresa possui estrutura formal de reportem sistemas formais e informais de planejamento, controle e coordenação (recursos organizacionais), além de mensurar os níveis de produção por meio do controle de qualidade, buscando sempre alcançar a eficiência e a eficácia. Isso ajuda a empresa a explorar os recursos valiosos e custosos de imitar, o que the garante tal implicação competitiva, mesmo não operando com $100 \%$ de capacidade, o que vai acontecer em seis meses de acordo com o entrevistado.

Os recursos valiosos citados pelo entrevistado foram três: os recursos humanos, um software e a máquina de corte a laser. Em relação aos recursos humanos a Empresa A tem procurado treinar os colaboradores e garimpar profissionais com qualificações, conhecimento e que sejam inovadores, criativos e proativos. O software que a empresa utiliza auxilia em diversos setores da empresa e que permite trazer informações importantes sobre vendas. Enquanto a máquina de corte a laser ajudar a dar mais precisão no corte, refletindo na qualidade do produto final.

Em relação à raridade, os recursos que a empresa possui não são raros, o Entrevistado $A$ chega a dizer que não pode menosprezar, subestimar o concorrente quanto a esse tema. Sobre a imitabilidade dos recursos e capacidades, o Entrevistado A diz que estes são difíceis de imitar ou desenvolver por duas questões: o conhecimento e a tecnologia. Ele dá mais ênfase na sua justificativa à máquina de corte, para isso afirma que '[...] ela faz o corte perfeito, o que isso vai trazer para o meu produto final? Vai ter uma camisa que ela vai está perfeita nos ajustes, por exemplo, uma camisa listrada. Às vezes você compra a camisa listrada e as listas não se batem, no meu caso o laser corta tão perfeito que a minha camisa que é listrada, tanto vertical como horizontal, ela vai estar casando na costura, certinho'.

Duas perguntas em relação ao tema abordado na pesquisa foram levantadas: a primeira sobre o interesse da Empresa A sobre o assunto abordado nesta pesquisa; e se era importante estudar a vantagem competitiva, justificando as respostas. Assim, sobre a relevância do estudo sobre os temas aqui abordados, o Entrevistado A diz, em relação à primeira pergunta: 'Veja bem, é importantíssimo estudar vantagem competitiva hoje, porque hoje a gente tem hoje um mercado que muda constantemente, diariamente'.

Posteriormente, seguindo a mesma linha de raciocínio, diz: '[...] então se você não pesquisar, se você não ser criativo, proativo, você vai ficar para trás, porque o mercado hoje, por conta da informação, é muito rápido, exige que a empresa ela também se adeque rapidamente, porque se ela não acompanhar, se ela não tiver no mesmo ritmo é como você pegar uma Ferrari e um fusquinha, 'num' é, e 'botar' numa corrida, vai ser uma concorrência desleal, então é isso que todas as empresas hoje tem que obter, sucesso. A gente tem que 'tá' antenado na informação, quem tem a informação, o conhecimento hoje detém o mercado'.

Sobre a segunda pergunta, ele diz: 'Sim, porque isso vai trazer para mim pontos, ou melhor, ferramentas de proposta, de talvez, neutralizar as ameaças que possa aparecer, então, uma pesquisa como essa, além de me instigar a melhorar, ela também me mostra caminhos para que possa melhorar, ser mais eficiente e eficaz'. Estes foram os resultados alcançados na Empresa A conforme a entrevista realizada com o Entrevistado A e de acordo com os objetivos específicos desta pesquisa. 


\section{Empresa B}

Os recursos tangíveis identificados foram: máquinas e equipamentos; a estrutura; a localização; as lojas; a fábrica; recursos financeiros; matéria-prima. Os recursos intangíveis identificados na empresa foram: recursos individuais (pessoas); e softwares. Estes recursos citados pela Entrevistada B são considerados forças para a Empresa B, uma vez que a empresa '[...] tem muito equipamento, pessoas que trabalham bem, onde cada um procura fazer o seu melhor, eu acho que isso é forte e faz com que um concorrente não tenha. [...] a gente tem uma equipe muita boa e a gente sempre tá atualizando, tanto os equipamentos, quanto os profissionais. São cursos toda semana, a gente viaja e vai estudar fora, todo mundo, não tem só um setor não'.

Apesar de a Entrevistada B identificar que os recursos são uma força, estes, na verdade são uma fraqueza, pois, de acordo com Barney et al. (2007), recursos não valiosos são fraquezas para a empresa e foi isso que os resultados do modelo VRIO indicaram. Os recursos e capacidades da empresa são considerados pela Entrevistada B como sendo estratégicos, uma vez que tudo faz parte da estratégia de crescimento da empresa. Ainda, o diagnóstico dos recursos em comparação com os recursos dos principais concorrentes aponta que, em relação ao principal concorrente, a Empresa C, a Empresa B possui um equipamento de enfesto de tecido que esta não possui.

Sobre a marca da empresa como um recurso que pode proporcionar uma vantagem competitiva, sobre a consolidação, a forma como impacta no negócio da empresa e como é ela desenvolvida (FAVORETO; VIEIRA, 2014), a Entrevistada B afirma que '[...] a marca hoje em dia ela é jovem'. Sobre a consolidação da marca, ela afirma que '[...] a gente ainda 'tá' no posicionamento, a gente trabalha essa parte de marketing'. Sobre os outros pontos, não foi possível levantar as informações desejadas porque a Entrevistada B não soube responder.

Em relação à alocação e desenvolvimento dos recursos conforme as estratégias existentes, e de acordo com a estrutura da empresa, a Entrevistada B afirma que isto é feito para a loja. Ela diz que todas as lojas foram modificadas, foi feito um trabalho de marketing. Toda a equipe de produção também foi mudada, além de aquisição de novos equipamentos para a produção. Ainda, a empresa está com um pessoal para identificar gargalos na produção e poder dar mais agilidade, como também está com uma equipe de vendas externas, tudo em conformidade com as estratégias existentes.

Estes recursos citados ainda precisam ficar compatíveis e se relacionarem de forma colaborativa, para isso, a Empresa B tem capacitado seu pessoal para estar aptos a lidarem com coisas novas, fazendo com que estes vejam como aquilo é importante para eles. A importância destes recursos é avaliada por meio da otimização de tempo e melhorias na qualidade do produto. A Empresa B desenvolve seus recursos por meio da compra, uma vez que estes já estão prontos, e capacitando as pessoas.

A fim de melhorar produtos e processos a Empresa B investe em Pesquisa \& Desenvolvimento, alocando recursos para atualizar processos, profissionais e equipamentos. Quanto ao conjunto de recursos da empresa ser facilmente transferido para outra empresa, a Entrevistada A acredita que não. Ela justifica sua resposta afirmando que isso não seria possível por causa das pessoas. Para que estes recursos não sejam 
transferidos ou copiados é preciso protegê-los, porém há medidas de proteção quanto para isso. Sobre as implicações competitivas propostas por Barney et al. (2007) usando o modelo VRIO. A implicação competitiva encontrada na empresa, baseado no modelo VRIO, é que esta possui uma desvantagem competitiva. Conforme Barney et al. (2007):

[...] se um recurso ou capacidade controlado por uma empresa não é valioso, ele não permitirá que a empresa escolha ou implemente estratégias que exploraram oportunidades ou neutralizem ameaças ambientais. Organiza-se para explorar esse recurso aumentará os custos da empresa ou diminuirá suas receitas. Esses tipos de recursos são fraquezas. Se as empresas realmente explorarem esses recursos e capacidades, o esperado é que se coloquem em desvantagem competitiva, se comparada a empresas que não possuem recursos poucos valiosos ou não os utilizam ao criar e implementar suas estratégias. (BARNEY et al. 2007)

O resultado encontrado é justificado na entrevista, uma vez que, de acordo com a Entrevistada B, '[...] a empresa trabalha com o que todo mundo trabalha 'né', a questão é só a qualidade mesmo que a gente procura os melhores tecidos, [...] nada que ninguém não faça'. Conforme Barney et al. (2007) recursos que não sejam valiosos à empresa não permitem que uma oportunidade seja explorada, tampouco neutralizar uma ameaça.

Sobre a raridade dos recursos, a Entrevistada B cita o software 'Audaces' (software que faz modelagem computadorizada, auxiliando no encaixe, risco e corte dos tecidos) que dá praticidade, facilidade e rapidez no corte, o que proporciona redução no tempo, porém este software já é trabalhado em outras empresas, estas que, por ser acessível, o compram e o incorporam ao seu conjunto de recurso.

Sobre um recurso raro ser fonte de vantagem competitiva, a Entrevistada B afirma que com o 'Audaces' o tempo de produção diminui como também há mais qualidade no produto final, proporcionando vantagem à empresa. Apesar de a entrevistada acreditar que este software confere a empresa vantagem competitiva, isto não acontece, até mesmo porque outras empresas também possuem este mesmo software. Quanto aos recursos e capacidades serem imitáveis, a Entrevistada B afirma que é possível comprar os recursos ou capacitar as pessoas, isso, se tratando do software 'Audaces'. Ela afirma que muita gente sabe do programa, logo pode comprá-lo.

Por último a questão da organização, onde, para esta, a Entrevistada B afirma que a empresa está organizada, é uma empresa que está no mercado há dez anos já. Ela ainda diz que a empresa passa por melhorias diárias, sempre tem uma coisa nova, logo vai comprando e capacitando as pessoas para que a organização explore estes recursos e capacidades. Porém, apesar de estar organizada, os recursos da empresa não são valioso, nem raros, tampouco difíceis de imitar, o que acaba sendo uma fraqueza para empresa e a colocando em desvantagem competitiva frente aos concorrentes.

Por fim, duas perguntas em relação ao tema abordado na pesquisa foram levantadas: a primeira sobre o interesse da Empresa B sobre o assunto abordado nesta pesquisa; e a se era importante estudar a vantagem competitiva, justificando as respostas. Assim, sobre a relevância do estudo sobre os temas aqui abordados, a Entrevistada B diz, em relação primeira pergunta: 'Assim, eu fiquei curiosa, só que eu 'tô' perdida ainda, não vou mentir, que 'tá' muito vago, eu preciso entender as coisas, mas assim, é muito interessante'. Sobre a segunda pergunta, ela responde e justifica ao dizer que "sim, é importante pra gente 
não ficar para trás 'né', mas assim, é muito interessante, tem que ver o que 'tá' acontecendo para melhorar sempre'.

\section{Empresa C}

Os recursos tangíveis identificados na empresa foram: matéria-prima; automóveis; máquinas de última geração; loja; e fábrica. Os recursos intangíveis identificados na empresa foram: valor agregado da marca; softwares; conhecimento dos colaboradores; e recursos organizacionais. Estes mesmos recursos podem ser agrupados em quatro categorias como proposto por Barney et al. (2007).

Os recursos identificados na Empresa C são considerados forças, principalmente o designer próprio e a questão de a empresa ser familiar. Embora sejam forças para a empresa, esta não busca diagnosticar os recursos que possui em comparação com os dos principais concorrentes. Ainda, destes recursos, aquele considerado estratégico é o valor agregado da marca, esta que é reconhecida no mercado, para isso, conforme o entrevistado:

Eu acredito que a (nome da empresa) é a camisaria que tem o melhor custo-benefício atualmente no mercado, ela é uma camisaria mais cara que do que as outras no valor, falo colocando o valor, medindo o valor, mas a questão do custo-benefício é uma coisa bem desproporcional mesmo, eu acho que esse é o grande diferencial.

Quando perguntado se a Empresa C possuía uma marca consolidada e reconhecida no mercado, o Entrevistado C disse que '[...] determinadas regiões sim, não em âmbito nacional'. A marca ser consolidada no mercado ajuda para que esta fique reconhecida, assim é preciso desenvolvê-la, para isso a Empresa $C$ faz algumas parcerias no segmento onde ela é forte. São desenvolvidas propagandas nas redes sociais, rádio, televisão. $\mathrm{O}$ Entrevistado $\mathrm{C}$ fala que a empresa fez uma parceria com a revendedora de roupas de Fortaleza para estar dentro de um projeto em que o cantor Wesley Safadão estaria participando junto com este cliente da Empresa C.

Estes mesmo recursos são alocados e desenvolvidos levando em consideração as estratégias existentes e de acordo com a estrutura da empresa, sendo, ainda, fonte de elaboração das estratégias organizacionais. A Empresa C adotou uma estratégia de, nos dois últimos meses do ano, não comprar mais matéria-prima; utilizar o que já está sob a sua posse. Essa estratégia busca não imobilizar os recursos financeiros e assim poder planejar a alocação de recursos em um segmento de roupa.

É preciso que recursos e capacidades fiquem compatíveis e se relacionem de forma colaborativa, para isso, o Entrevistado C afirma que a empresa tenta comprar o que é necessário e treinar os colaboradores para que possam manipular equipamentos e máquinas. Estes treinamentos são realizados remotamente, via 'timeview' e Skype, uma vez que os equipamentos são comprados fora do estado, assim a empresa já começa a preparar tudo.

Em relação aos designers como recursos da empresa, as habilidades destes são desenvolvidas por meio de investimentos em eventos do setor de moda, como também adequando o local de trabalho para que possa influenciar na motivação e na criatividade da equipe de criação de peças. A empresa C consegue, ainda, proteger este recurso essencial por meio do aumento do salário, ou seja, o protege financeiramente. 
A melhoria de produtos e processos na empresa se dá por meio de Pesquisa e Desenvolvimento. Para que isto aconteça, o Entrevistado $\mathrm{C}$ diz que a empresa está sempre participando de feiras de maquinário. Em uma destas feiras, a de Fortaleza, a empresa adquiriu o sistema que a empresa utiliza atualmente, o sintextil. Ele também cita um mecânico da empresa que sempre está atento às formas de melhorar processos.

Sobre a possibilidade de os recursos da empresa ser transferidos facilmente, o entrevistado afirma que não é possível. Porém, o entrevistado se contradiz, ele afirma que, apesar de pouco provável transferir os recursos, talvez fosse possível transferir estes se a empresa fosse do mesmo segmento. A importância dos recursos no desempenho da empresa é avaliada pela diminuição de custo. $\mathrm{O}$ Entrevistado $\mathrm{C}$ diz que quando a empresa compra um equipamento, é visto a questão da redução nos custos dos produtos finais e também é observado o tempo de payback do investimento realizado, ou seja, o tempo em que a máquina irá se pagar. Para proteger seus recursos ela os protege financeiramente, no caso dos designers.

Conduzindo a pesquisa sobre vantagem competitiva sob a luz da teoria RBV, o modelo VRIO foi aplicado na Empresa C para se identificar o tipo de implicação competitiva que está possuí. A empresa possui uma vantagem competitiva temporária diante dos concorrentes, o que também se caracteriza como uma força e competência distintiva. Uma vez que a empresa possui recursos valiosos, raros, difíceis de imitar, mas que a organização ainda não está organizada para aproveitar ao máximo o potencial competitivo destes, a empresa acaba tendo uma vantagem competitiva temporária.

Os recursos valiosos citados pelo Entrevistado C foram os designers da empresa e o conhecimento de um dos seus irmãos, que trabalha na parte comercial e no designer, considerado os recursos mais importantes. O conhecimento do irmão do Entrevistado C está ligado ao cliente, ao feedback muito mais rápido que a empresa consegue graças a este recursos citado, além de estar envolvido no design dos produtos também. Outro recurso valioso para a Empresa $C$ e considerado um diferencial é a questão de a empresa ser familiar, sendo bastante dedicada ao negócio. Há uma máquina valiosa para a empresa que faz um acabamento quase perfeito e que pouquíssimas empresas possuem; esses recursos também são valiosos.

A Empresa $\mathrm{C}$ ainda está adquirindo uma máquina para auxiliar e melhorar a produção de camisa gola Polo. Mais um recurso valioso identificado são os equipamentos denominados pelo Entrevistado como 'aparelhos'. Estes auxiliam a empresa na redução de processo, onde este pode fazem três operações em uma única. Este aparelho custa em $\mathrm{R} \$ 600,00$ e a empresa possui aproximadamente 100 destes. Os últimos recursos considerados valiosos para a empresa foram os softwares Audaces, que custa em média $R \$ 36 \mathrm{mil}$, e o software de gerenciamento que é usado na produção. No faturamento a empresa utiliza o sintextil, mesmo programa utilizado pela maior empresa de confecção da América Latina, a Guararapes.

Estes recursos valiosos permitem a exploração de uma oportunidade e neutralização de uma ameaça externa. A Empresa $\mathrm{C}$ possui alguns equipamentos raros no mercado, estes equipamentos ajudaram a aproveitar uma tendência que estava surgindo no mercado: a flocagem. A flocagem se trata de uma tinta aveludada usada em estampas e que a Empresa $C$ foi a primeira a aproveitar esta oportunidade graças aos seus recursos valiosos. Sobre neutralizar uma ameaça, o Entrevistado $\mathrm{C}$ afirma que o poder de barganha da empresa faz com que alguns tecidos sejam exclusivos da empresa. Essa resposta pode ser a marca da 
empresa como forma de neutraliza a ameaça dos concorrentes desleais, uma vez que estes não conseguem ter este mesmo recurso.

Sobre a raridade dos recursos, o Entrevistado $C$ afirma que duas empresas da região podem ter determinados recursos que a empresa possui, a Rota do Mar e Joggofi. Ele acredita que estas empresas conseguem estes recursos ao longo prazo com capital de giro e investimento. Embora o Entrevistado $\mathrm{C}$ tenha citado que duas empresas possam ter determinados recursos e capacidades, Barney (1991) e Barney et al. (2007) dizem que um recurso é raro quando ele é exclusivo ou está sob a posse de poucas empresas do setor, logo os recursos da empresa são raros. Ainda conforme Barney et al. (2007), um recurso raro pode ser uma fonte de vantagem competitiva para a empresa. Quanto a isso o Entrevistado C corrobora e diz que 'você tem que fazer o diferencial, se fizer só feijão com arroz não dá mais, não satisfaz'.

Os recursos da Empresa C são difíceis de imitar, impondo alguma desvantagem para outras empresas obtê-los ou desenvolvê-los. De acordo com o Entrevistado C, 'quanto mais você compra mais você tem barganha, você consegue um preço menor'. A fala do entrevistado levanta a hipótese de que o recurso que proporciona isto são os recursos financeiros, uma vez que a empresa tem poder de barganha sobre fornecedores. Ele ainda acredita que o investimento inicial é alto para ter uma estrutura igual à que a empresa possui. Sem contar que é um investimento ao longo prazo e arriscado, não é um valor que os concorrentes investem e tem um retorno fácil, é muito imprevisível.

A questão da organização é o que leva a empresa a ter uma vantagem competitiva temporária, uma vez que está ainda não está organizada plenamente para explorar ao máximo o potencial competitivo de seus recursos e capacidades, porém a empresa consegue se destacar mesmo assim. O motivo de a Empresa C ainda não estar $100 \%$ organizada é que todas as unidades produtivas não são próprias, assim, a logística fica comprometida. A Empresa $C$ possui quatro unidades produtivas espalhadas pelo bairro onde está localizada, porém o gerenciamento dessas unidades fica comprometido.

Embora a Empresa C ainda não esteja organizada 100\%, principalmente na parte física, esta possui recursos organizacionais, tais como estrutura formal de reporte, sistemas formais e informais de planejamento, controle e coordenação. Além disto, já está com um terreno próprio onde dará início a construção de sua fábrica própria, o que vai, de acordo com o Entrevistado C, permitir que a empresa veja onde está pecando, além de reduzir o custo fixo e, consequentemente, o preço dos produtos.

Duas perguntas em relação ao tema abordado na pesquisa foram levantadas: a primeira sobre o interesse da Empresa $\mathrm{C}$ sobre o assunto abordado nesta pesquisa; e a se era importante estudar a vantagem competitiva, justificando as respostas. Assim, sobre a relevância do estudo sobre os temas aqui abordados, o Entrevistado C diz despertar o interesse sobre o assunto abordado na pesquisa, ele fala que é importante para '[...] saber em que segmento a gente 'tá', conhecer os concorrentes e saber qual o nosso diferencial em relação aos outros, isso é o essencial'. Estes foram os resultados alcançados na Empresa A conforme a entrevista realizada com o Entrevistado A e de acordo com os objetivos específicos desta pesquisa. Por fim, sobre a importância em se estudar a vantagem competitiva, o Entrevistado C diz que:

Sim, lógico. Você saber o que é o diferencial de você 'pras' outras começa a dá um cuidado maior aquele determinado assunto né, então acho que isso é o essencial né, você saber o 
que você tem de diferencial e não deixar, como você falou, 'neutralizar', então você não deixar os outros nem começarem a fabricar, porque como eu falei, a confeç̧ão é um investimento a longo prazo, então quando você começa você pode começar pequeno, só que você começa pequeno mas na confecção você vai ganhando o cliente, então você tem que neutralizar o concorrente antes de ele começar, então é bem bacana você saber onde você 'tá', o que você precisa continuar fazendo pra não perder mercado e nem deixar os outros começarem.

\section{Empresa D}

Os recursos tangíveis identificados foram: matéria-prima; produtos; a loja; pessoas; e máquinas. Os recursos intangíveis identificados foram: cultura organizacional; posicionamento de marca; comunicação de marketing; branding; estratégias de marketing; softwares. Os recursos citados são considerados, de acordo com o Entrevistado D, forças para a Empresa D. Ele diz que '[...] eles expressam tudo o que a gente conseguiu até hoje né. São dois anos de empresa, então a gente tem tanto os recursos intangíveis, quanto os tangíveis. Então a gente considera como força'.

Destes recursos, além de forças, alguns são estratégicos, como, por exemplo, o marketing digital, onde este ajuda a posicionar a marca no mercado. A importância destes recursos é avaliada por meio do fracasso ou sucesso que estes conferem. Sobre a marca da empresa como um recurso que pode proporcionar vantagem competitiva, não foi possível identificar se a marca da empresa tem potencial para proporcionar uma vantagem competitiva. Em relação à marca da empresa ser reconhecida no mercado, o Entrevistado $D$ diz que busca isso. Estes recursos são desenvolvidos na produção, na valorização de fazer bem-feito o produto, para isso, a Empresa D investe na criação, é um investimento financeiro não formalizado.

Embora os recursos citados sejam considerados forças, a Empresa D não costuma realizar diagnóstico dos recursos que possui em comparação com os dos principais concorrentes. O que é feito são deduções por meio das comparações entre os produtos, realizadas pelos clientes que compram nos concorrentes. Estes recursos são alocados ou desenvolvidos conforme a realidade da Empresa D, estando alinhados ao que a empresa consegue fazer. Para que estes recursos e capacidades fiquem compatíveis e se relacionem de forma colaborativa, é adotado um acompanhamento total, ou seja, uma visão holística de tudo que acontece, desde a chegada da matéria-prima até o pós-venda. Os recursos citados são forças para a Empresa $D$ e alguns são estratégicos, porém não há medidas para proteger estes recursos.

As implicações competitivas identificadas na Empresa D de acordo com o modelo VRIO serão apresentadas a seguir. De acordo com os resultados da pesquisa, a Empresa D possui uma paridade competitiva em relação aos outros concorrentes no mercado, uma vez que possui recursos valiosos e custosos de imitar, porém não são raros nem a empresa está totalmente organizada para aproveitar ao máximo o potencial competitivo destes recursos. O recurso valioso identificado foi o branding, sendo considerado o recurso mais importante, a gestão da marca. Embora os recursos da Empresa D não sejam raros, o Entrevistado D a acredita que um recurso raro no mercado pode ser uma fonte de vantagem competitiva, uma vez que '[...] fortalece ainda mais a identidade da marca ou do produto'.

Os recursos e capacidades são difíceis de imitar, em relação ao produto. O que torna os produtos da Empresa $D$ difíceis de imitar e os diferenciam é o design da estampa ou a composição das malhas. Ele diz que 
'[...] as malhas ele pode até ter acesso né, ir aos fornecedores, mas às estampas, o design, o que vai da criação, vai da ideia, então isso ele não pode imitar né, e se ele não pode ele vai ter uma desvantagem' . 0 Entrevistado $D$ ainda enfatiza que os concorrentes '[...] podem imitar os produtos, mas não as ideias, a identidade, a maneira de ser da empresa'.

A organização procura se esforçar para ter efetividade nas funções, buscar fazer muito com pouco, neste caso a empresa explorar o potencial competitivos de seus recursos e capacidades, porém poderia explorar ainda mais, o que caracteriza que a empresa ainda não explora ao máximo o potencial competitivo de seus recursos e capacidades. $O$ Entrevistado $D$ afirma que poderia explorar ainda mais a organização caso tivesse uma equipe maior, se tivesse alguns outros recursos que exigem um capital a mais.

A Empresa D também não possui recursos organizacionais como estrutura formal de reporte, sistemas formais e informais de planejamento, controle e coordenação. Duas perguntas em relação ao tema abordado na pesquisa foram levantadas: a primeira sobre o interesse da Empresa $D$ sobre $o$ assunto abordado nesta pesquisa; e a se era importante estudar a vantagem competitiva, justificando as respostas. Assim, sobre o interesse no tema desta pesquisa, o Entrevistado D diz:

Desperta, porque, como eu falei, a vantagem competitiva, quando a gente tem uma vantagem competitiva isso a gente pode até mesmo mensurar nos resultados né, até mesmo com o lucro da empresa ou com a sobrevivência dela né, então quando a gente tem algo que nos diferencia do concorrente, por exemplo, a gente vê nos próprios clientes falando né, e, até mesmo a gente percebe que o concorrente começa a te imitar, então isso às vezes são sinais que certificam né, que a gente tá no caminho certo e que você, direcionar sua empresa, as estratégias da sua empresa pra valorizar e querer investir na estratégia nessa da vantagem competitiva é o melhor caminho.

Sobre a importância de se estudar a vantagem competitiva, ele diz que acha importante e justifica dizendo '[...] porque se a gente for querer ser mais um no mercado é melhor não existir, a gente tem que 'tá' pra se destacar. Vamos dizer assim, para ter algum sucesso tem que ter essa vantagem competitiva, não tem outro caminho'.

\section{Empresa E}

Os recursos tangíveis identificados foram: matéria-prima; máquinas modernas e equipamentos; estrutura; frota de veículos; e recursos financeiros. Os recursos intangíveis identificados foram: marca; software; e conhecimento dos colaboradores. Estes recursos citados pelo Entrevistado E são considerados forças para a Empresa E, principalmente as pessoas. Ele acredita que quando se possui uma equipe entrosada, bem preparada e produtiva ela por si só faz com que a coisa ande. Destes recursos, aquele considerado estratégico é o software de criação que faz toda a diferença tanto na produtividade quanto na redução de custos, sendo muito eficaz nestas situações, porém estes não são protegidos.

Embora se apresentem como forças, a Empresa E não busca realizar um diagnóstico dos recursos que possui em comparação com o dos principais concorrentes. O que ela faz é uma análise do produto final do concorrente com base em conhecimento empírico, com isso se sabe mais ou menos a estrutura da empresa. A importância dos recursos no desempenho da Empresa E é avaliada por meio do aumento no lucro, para isto, esta busca recursos que auxiliem no aumento da produtividade da empresa e corrobore no lucro. 
Os recursos são desenvolvidos conforme a necessidade, para isso a Empresa E investe de acordo com a necessidade, seja comprando uma máquina, seja na contratação de pessoal. Ainda, os recursos são alocados e desenvolvidos conforme as estratégias existentes e de acordo com sua estrutura. Para isso, o Entrevistado E afirma que '[...] a gente sempre desenvolve o produto ou uma coleção dentro da capacidade da empresa, dentro do maquinário que eu tenho, dentro da mão-de-obra que eu tenho. Então tudo é desenvolvido dentro disso aí. Sobre a marca da empresa como um recurso que pode proporcionar uma vantagem competitiva, sobre a consolidação da marca, forma como essa impacta no negócio da empresa e como ela é desenvolvida, o Entrevistado E diz:

\begin{abstract}
A marca ela é uma identidade do produto, feito cada pessoa tem sua identidade, tem seu CPF. Ela é uma coisa que o cliente vai identificar no que ele deseja, a marca é isso. Acredito que sim. A visualização da marca ela tem que ser constante, em tudo, ou em rede social, ou em uma propaganda, ou num banner, ou num outdoor, isso tem que ser sempre trabalhado pra que o cliente não dispense, entendeu, essa atenção que ele tem da marca, porque se tiver essa persistência, a marca vai cair no esquecimento. De forma essencial, a marca é essencial para o produto.
\end{abstract}

Uma vez que todo projeto tem um tempo para se chegar à produtividade exata e para se chegar nesta produtividade desejada é preciso treinar um operador, porém demanda tempo, a Empresa E, conforme o Entrevistado E, investe em treinamento para adaptar o operador à máquina. Quando muda uma coleção, muda a operação também, aí começa tudo do zero novamente.

A Empresa E possui setor de Pesquisa \& Desenvolvimento que vê o que está na tendência no momento. $\mathrm{O}$ Entrevistado $\mathrm{E}$ afirma que esse setor não requer um investimento num setor específico porque a moda ela é muito acessível, 'independente' de qualquer coisa, a moda ela está na internet, na televisão, por isso ela é muito acessível.

Sobre a possibilidade de o conjunto de recursos da Empresa E ser facilmente transferido para outra, o Entrevistado E acredita que isso seria possível, porém alcançar o mesmo resultado dependeria muito da gestão. A Empresa E ainda utiliza os recursos e capacidades como fonte para elaboração das estratégias organizacionais.

Se tratando das implicações competitivas propostas pelo modelo VRIO, a Empresa E possui paridade competitiva, o que se caracteriza, também, como uma força, uma vez que possui recursos valiosos e difíceis de imitar, porém não raros e que essa ainda não está organizada totalmente para explorar ao máximo o seu potencial competitivo. $\mathrm{O}$ recurso valioso mencionado pelo Entrevistado $\mathrm{E}$ foi à equipe capacitada, pois se trata de uma equipe antiga na empresa que já têm experiência, sabe como é o manejo e a forma da empresa trabalhar

Quanto à raridade, o Entrevistado $\mathrm{E}$ afirma que há outras empresas que possuem determinados recursos e capacidades valiosos que a empresa também possui, sendo estes a matéria-prima. Ele ainda afirma que um recurso raro no mercado pode ser uma fonte de vantagem competitiva, porém no segmento de moda, de roupa, é difícil ter esse produto. Ainda afirma que '[...] o produto começa a vender aqui fulano já vai e corre atrás' , '[...] você não tem como ser exclusivo'.

'Quem não tem uma mão-de-obra qualificada ele tem uma dificuldade e eles ficam para trás, seja na produtividade, seja na qualidade', é o que diz o Entrevistado E sobre os recursos raros, mostrando que o 
recurso individual dos colaboradores é difícil de imitar. A Empresa E, na parte organizacional, não está organizada para explorar ao máximo o potencial competitivo dos recursos de acordo com o Entrevistado E. Ele afirma que '[...] ainda precisa de melhoras, precisa organizar mais'.

Duas perguntas em relação ao tema abordado na pesquisa foram levantadas: a primeira sobre o interesse da Empresa E sobre o assunto abordado nesta pesquisa; e a se era importante estudar a vantagem competitiva, justificando as respostas. Assim, sobre o assunto abordado na pesquisa despertar o interesse da empresa, o Entrevistado E diz que 'tem interesse sim, porque eu não tenho esse dado, eu tenho interesse em conhecer, de saber como é'.

Sobre a importância de se estudar a vantagem competitiva, o Entrevistado E diz que é importante e justifica dizendo que ela (a vantagem competitiva) 'é importante, não para você ser sempre o primeiro no mercado, mas para você não ser o último, 'tá entendendo', para você não ficar para trás. Quando você fica para trás, para acompanhar é mais difícil ainda'.

\section{CONCLUSÕES}

O cenário organizacional tem visto aumentar as discussões acerca da vantagem competitiva. Este é um campo que tem ganhado atenção dos pesquisadores e que ainda apresenta lacunas a serem preenchidas. Neste sentido, o Polo de Confecções do Agreste de Pernambuco se apresentou como uma realidade propícia para se conduzir uma abordagem baseada em recursos e capacidades. Assim, a presente pesquisa identificou nas empresas pesquisadas os pressupostos da Resourced-Based View, bem como as forças do ambiente geral e as forças e fraquezas das empresas, assim como as oportunidades e ameaças presentes no ambiente externo.

A pesquisa alcançou o seu primeiro objetivo, pois conduziu uma retrospectiva histórica sobre o Polo e as principais cidades produtoras de confecção (com destaque para Caruaru, Santa Cruz do Capibaribe e Toritama), apresentando dados sobre máquinas, produção, mão-de-obra, admissões e demissões, entre outros, o que possibilitou apresentar dados recentes do setor, bem como corroborar com dados de pesquisas anteriores como, por exemplo, a pesquisa do Sebrae (2012).

Em segundo, a pesquisa alcançou resultados satisfatórios e dentro dos parâmetros estabelecidos pela teoria RBV. Por meio da análise das empresas, é possível afirmar que seu conjunto de recursos é heterogêneo, mesmo estas atuando no mesmo setor, o que permite que as empresas produzam roupas de maneiras diferentes (BARNEY, 1991; PETERAF, 1993; BARNEY et al., 2007), mesmo alguns recursos sendo comuns para algumas empresas (alguns softwares, máquinas e a matéria-prima), as empresas não possuem os mesmo recursos, sejam eles tangíveis ou intangíveis. Alguns recursos são únicos da empresa, por exemplo, a cultura organizacional da Empresa $\mathrm{D}$, o recurso familiar e a marca da Empresa $\mathrm{C}$ e a máquina de corte a laser da Empresa A. Além do que as empresas se utilizam dos seus recursos e capacidades como fonte para a elaboração das estratégias organizacionais (GRANT, 1991).

A relação entre produtos e recursos mostrou que as empresas trabalham com produtos diversificados que necessitam de um conjunto de recursos diferentes, mas que se relacionam entre si, estes 
recursos sendo: a matéria-prima, a fábrica, as máquinas e equipamentos (recursos físicos); as pessoas (recursos individuais); o capital (recursos financeiros); e softwares e sistemas organizacionais (recursos organizacionais) (BARNEY et al., 2007). A posse destes recursos pode ser considerada duas faces da mesma moeda, uma vez que os produtos comercializados pelas empresas requerem o uso de muitos recursos, como também os recursos podem ser usados em muitos produtos (WERNERFELT, 1984).

Alguns recursos das empresas têm sua mobilidade imperfeita por ser um recurso valioso onde atualmente está sendo utilizado, ou seja, este recurso pode até ser transferido, mas os resultados alcançados na empresa em que atualmente está sendo usados são mais eficientes do que se fosse transferido para outra empresa, por questões como a estrutura da empresa, as pessoas envolvidas, o modelo de gestão e a produtividade (PETERAF, 1993). Observa-se que o fato de as empresas terem máquinas modernas e, principalmente, pessoas capacitadas e treinadas é muito importante para garantir um produto de qualidade. As pessoas são a principal força motriz das empresas pesquisadas quando alinhados aos outros recursos e capacidades da empresa.

Dos recursos propostos na pesquisa, para a indústria de confecção no Polo de Confeç̧ão do Agreste de Pernambuco, se sobressaem como estratégicos: o software de frente de loja e retaguarda (Empresa A), todo o conjunto de recursos da empresa (Empresa B), o valor da marca (Empresa C), o marketing digital (Empresa D) e o software de criação (Empresa E).

O objetivo da pesquisa de analisar o modelo VRIO com as empresas estudadas mostrou que as empresas que melhor satisfazem as condições do modelo proposto conseguem uma posição superior em relação aos concorrentes. No caso, duas empresas (A e C) alcançaram uma vantagem competitiva temporária, o que também se caracteriza como uma força e competência competitiva.

De modo geral, Os resultados alcançados mostraram que a maioria das empresas considera seus recursos valiosos. Apenas uma empresa possui recursos raros em relação a outras empresas. Quatro empresas consideram seus recursos difíceis ou custos de imitar, levando um concorrente à desvantagem. Sobre a organização, duas empresas estão organizadas para explorar ao máximo o potencial dos seus recursos, porém, um destas empresas não possuía recursos valiosos, raros e nem difíceis de imitar, o que já Ihe atribuía uma desvantagem competitiva.

Esse foi o intuito desse trabalho, aplicado às empresas da amostragem e confirmando que aqueles com recursos superiores têm uma vantagem competitiva e, consequentemente, crescem e se diferenciam no mercado em que atuam. Estar sob a posse de recursos estratégicos e que são valiosos, raros, difíceis de imitar e que a organização explora conduziram a pesquisa para os resultados apresentados. Espera-se que com os resultados aqui apresentados seja possível nortear as empresas para uma primeira visão sobre seus recursos e capacidades como fontes para a elaboração das estratégias organizacionais que culminem no alcance da vantagem competitiva, uma vez que não há estudos na região do Polo de Confecções do Agreste de Pernambuco sobre vantagem competitiva, porém há empresas com um desempenho superior.

Este estudo teve como limitação o acesso às empresas e o interesse em participar da pesquisa, esta que seria realizada com nove empresas de três segmentos diferentes (jeans, camisaria e moda praia) nas 
cidades de Toritama, Caruaru e Santa cruz do Capibaribe, cada uma, respectivamente, de acordo com cada segmento escolhido, porém as empresas convidadas para participar da pesquisa não responderam aos emails enviados, com exceção da Red Life, que respondeu e justificou a recusa.

Outra limitação foi em relação ao acesso a livros de autores clássicos, principalmente sobre estratégia e vantagem competitiva, motivado pela transferência da biblioteca da UFPE, Campus Caruaru para um novo espaço, bem como deflagração de uma greve dos técnicos da universidade. A pesquisa ainda encontrou limitações no que tange o acesso a estudos sobre vantagem competitiva na região do Polo de Confecções do Agreste de Pernambuco, uma vez que não foram encontrados estudos que tratassem de tal tema sob qualquer perspectiva teórica no âmbito organizacional.

A última limitação encontrada foi realizar a entrevista diretamente com o proprietário da empresa. Dos entrevistados da pesquisa, dois são proprietários da empresa, um é o diretor financeiro e sócio da empresa, um é gerente de uma das lojas da empresa e a outra pessoa é estilista da empresa. A disponibilidade do proprietário para participar da pesquisa foi um pouco complicada, porém se buscou, no caso dos entrevistados que não eram proprietários da empresa, realizar a entrevista com uma pessoa que pudesse trazer informações pertinentes à pesquisa.

Pesquisas futuras poderão abranger um campo maior de estudo e que ainda são poucos explorados em pesquisas, aplicando teorias de diversas áreas do campo da administração. Na área de estratégia algumas pesquisas ajudarão a enriquecer e trazer a luz das teorias organizacionais alguns fenômenos que se apresentam na prática, tanto nas empresas pesquisadas, quanto também na região como um todo. Estudar a cadeia de valor na indústria de confecção poderá trazer resultados importantes, tanto para o campo da estratégia, como também para organizações, uma vez que algumas das empresas estudadas na pesquisa terceirizam alguns ou todos os processos da produção.

Trabalhos futuros ainda poderão abordar um confronto entre o alcance da vantagem competitiva através de uma visão voltada para o ambiente interno e externo, ou seja, uma visão baseada nos recursos e uma visão baseada no setor onde a empresa está inserida. Um trabalho deste porte ajudará a enriquecer e complementar lacunas encontradas na pesquisa e que, aos olhos do pesquisador, enfraquecem a efetividade de ambos os modelos teóricos que estudam a vantagem competitiva ao passo que um modelo exclui o outro na construção da vantagem competitiva.

\section{REFERÊNCIAS}

ARIK, M.; CLARK, L. A.; RAFFO, D. M.. Strategic responses of non-profit organizations to the economic crisis: Examining through the lenses of resources dependency and resourcedbased-view theories. Academy of Strategic Management Journal, v.15, n.1, p.48-70, 2016.

\section{BARBOSA, R. A.. Estratégia de inovação à luz da visão} baseada em recursos: Um estudo na Embrapa. Dissertação (Mestrado) - Universidade Federal da Paraíba, João Pessoa, 2013.
BARNEY, J. B.. Firm resources and sustained competitive advantage. Journal of Management, v.17, n.1, p.99-120, 1991.

BARNEY, J. B.; HERSTERLY, W. S.. Administração estratégica e vantagem competitiva. São Paulo: Pearson Prentice Hall, 2007.

BAYRAKTAR, C. A.; HANCERLIOGULLARI, G.; CETINGUC, B.; CALISIR, F.. Competitive strategis, innovation, and firm performance: An empirical study in a developing economy environment. Technology Analysis and Strategic

Management, v.29, n.1, p.38-52, 2017. 
CNI. Confederação Nacional da Indústria. Perfil da Indústria nos Estados. Brasília: CNI, 2015.

CRUBELLATE, J. M.; PASCUCCI, L.; GRAVE, P. S.. Contribuições para uma visão baseada em recursos legítimos. Revista de Administração de Empresas, v.48, p.819, 2008.

CUNHA FILHO, M. R. O desenvolvimento de novos serviços (DNS) e a obtenção de vantagens competitivas sustentáveis: Estudo de caso em instituições bancárias no Brasil. Brasília: UnB, 2012.

EISENHARDT, K. M.; MARTIN, J. A.. Dynamic capabilities: what are they?. Strategic Management Journal, v.21, n.11, p.1105-1121, 2000.

FAVORETO, R. L.; VIEIRA, S. F. A.. A Produção Internacional em RBV: Características gerais e tratativa dos recursos na pesquisa em organizações de menor porte. Revista Iberoamericana de Estratégia, v.13, p.25-37, 2014.

GIL, A. C.. Como elaborar projetos de pesquisa. 4 ed. São Paulo: Atlas, 2002.

GODOY, A. S.. Introdução à pesquisa qualitativa e suas possibilidades. Revista de Administração de Empresa, v.35, n.2, p.57-63, 1995.

GOHR, C. F.; SANTOS, L. C.; BURIN, C. B.; MARQUES, M.; ARAI, R.. Recursos estratégicos e vantagem competitiva: aplicação do Modelo VRIO em uma organização do setor sucroalcooleiro. Revista Gestão Organizacional, v.4, p.115139, 2011.

GRANT, R. M.. The resourced-based theory of competitive advantage: Implications for strategy formulation. California Management Review, v.33, n.3, p.114-135, 1991

HOSKISSON, R. E.; EDEN, L.; MING, C.; WRIGHT, M.. Strategy in emerginge economics. Academy of Management Journal, v.43, n.3, p.249-267, 2000.

IEMI. Instituto de Estudos e Marketing Digital. Relatório Setorial da Indústria Têxtil Brasileira. São Paulo: IEMI, 2015.

KULL, A. J.; MENA, J. A.; KORSCHUN, D.. A resourced-based view of stakeholder marketing. Journal of Business Research, v.69, n.12, p.5553-5560, 2016.
LACERDA, A.. Agreste tem 2o maior polo têxtil do país. São Paulo: Estadão, 2013.

LAMB, L.; MORENO, M. C.; BECKER, G. V.. A análise dos recursos e capacidades utilizados por operadores logísticos segundo o modelo VRIO. In: ENCONTRO DE ESTUDOS EM ESTRATÉGIA, 4. Anais. Recife: 2009.

LIN, Y.; WU, L. Y.. Exploring the role of dynamic capabilities in firm performance under the resource-based view framework. Journal of Business Research, v.67, n.3, p.407413, 2014.

MARSHALL. C.; ROSSMAN, G. B.. Designing qualitative research. Thousand Oaks: Sage Publications, 2006.

OLIVEIRA, R. V.. O pólo de confecções do agreste de Pernambuco: ensaiando uma perspectiva de abordagem. In: ENCONTRO ANUAL DA ANPOCS, 35. Anais. São Paulo: ANPOCS, 2011.

PETERAF, M. A.. The cornestones of competitiva advantage: A Resourced-based view. Strategic Management Journal, v.14, n.3, p.179-191, 1993.

RIBEIRO, H. C.; COSTA, B. K.; MURITIBA, S. N.; OLIVEIRA NETO, G. C.. Visão baseada em recursos: uma análise bibliométrica dos últimos onze anos. Revista de Ciências da Administração, v.14, n.34, p.39-59, 2012.

SEBRAE/PE. Serviço Brasileiro de Apoio às Micro e Pequenas Empresas no Estado de Pernambuco. Estudo Econômico do Arranjo Produtivo Local de Confecções do Agreste Pernambucano. Recife: SEBRAE, 2012.

TEECE, D. J.; PISANO, G.; SHUEN, A.. Dynamic capabilities and strategic management. Strategic Management Journal, v.18, n.7, p.509-533, 1997.

VERGARA, S. C.. Projetos e Relatórios de Pesquisa em Administração. 12 ed. São Paulo: Atlas, 2010.

WERNERFLT, B. A.. A resourced-based view of the firm. Strategic Management Journal, v.5, n.2, p.171-180, 1984.

YIN, R. K.. Estudo de caso: planejamento e métodos. 2 ed. Porto Alegre: Bookman, 2001. 